\title{
PELATIHAN PENGGUNAAN GOOGLE CLASSROOM DALAM MENGOPTIMALKAN PEMBELAJARAN E- LEARNING PADA SDN 41 PALEMBANG
}

\author{
Asti Gumartifa*1, $^{1}$, Indah Windra Dwie Agustiani ${ }^{2}$, Bengawan Alfaresi $^{3}$ \\ Universitas Muhammadiyah Palembang \\ asti_gumartifa@um-palembang.ac.id ${ }^{1}$, indahwindra@yahoo.com ${ }^{2}$, begawan_alfarezi@um-palembang.ac.id ${ }^{3}$
}

\begin{abstract}
Abstrak
Ilmu adalah hal penting dalam meningkatkan mutu kecerdasan bagi setiap guru maupun murid. Hal itu tidak dapat dipisahkan dengan ICT (Internet, Computer, Teknologi) yang selalu berkembang dengan zaman. Dalam kegiatan pembelajaran untuk memperoleh ilmu setiap guru dan murid harus mampu meningkatkan mutu pengajaran dan pembelajaran dengan menggunakan teknologi secara optimal. Salah satu teknologi pembelajaran yang harus di terapkan dalam pembelajaran saat ini adalah dengan menggunakan E-learning. Salah satu contoh pembelajaran dengan menggunakan E-learning adalah Google Classroom. Metode pembelajaran dengan menggunakan Google Classroom memiliki banyak sisi positif. Sesuai dengan peraturan pemerintah pada masa Pandemi Corona saat ini untuk menghimbau guru tetap melaksanakan pembelajaran tetap secara aktif deng an melaksanakan pembelajaran melalui Google Classroom. Tujuan dari pengabdian masyarakat ini adalah memberikan pelatihan kepada guruguru SDN. 40 untuk dapat mengoptimalkan pembelajaran dengan menggunakan Google Classroom. Pada pelaksanaan pengabdian masyarakat tersebut menggunakan metode teori dan praktik. Hasil dari kegiatan pelatihan pada pengabdian tersebut adalah dapat memperkenalkan pengajaran yang efektif dan optimal secara daring. Sehingga guru dapat menoptimalkan penggunaaan Google Classroom secara mandiri. Pada akhirnya guru-guru dapat melakukan pengajaran dengan memberikan materi, tugas, kuis, menentukan nilai siswa dan menjadwalkan setiap kegiatan pembelajaran dengan fleksibel dan mandiri.
\end{abstract}

Kata kunci : google classroom, e-learning, ICT, pelatihan, pembelajaran

\begin{abstract}
Knowledge is important in improving the quality of intelligence for every teacher and student. It cannot be separated from ICT (Internet, Computer, and Technology) which is always evolving with the times. In learning activities to gain knowledge, each teacher and student must be able to improve the quality of teaching and learning by using technology optimally. One of the learning technologies that must be applied in today's learning is the use E-learning. One example of of E-learning is Google Classroom learning. The learning method using Google Classroom has many positive sides. Accordance with the government regulation during Pandemic of Covid-19. Teachers should be able to obtain active learning by carrying out learning through Google Classroom. The purpose of this devotion society is to provide training to teachers of SDN 40 to be able to optimize learning using Google Classroom. The implementation of this devotion society by using theoretical and practical methods. The result of the training activities in this service is to introduce effective and optimal teaching and learning online. Thus, teachers can optimize the use of Google Classroom independently. In the end, teachers can conduct teaching by providing materials, assignments, quizzes, determining student grades and scheduling each learning activity flexibly and independently.
\end{abstract}

Keywords - Google classroom, e-learning, ICT, training, learning

\section{PENDAHULUAN}

Pelaksanaan Pengabdian pada Masyarakat (PKM) ini adalah lanjutan dari observasi pada SDN 41 mengenai kesiapan guru pada perubahan metode pembelajaran di masa Pandemi Covid -19. Pada lanjutan pelatihan pengenmbangan metode pembelajaran ini adalah memberikan 
Seminar Nasional Penelitian dan Pengabdian kepada Masyarakat Universitas Sang Bumi Ruwa Jurai Tahun 2020

dampingan kepada seluruh guru di SDN 41 agar memiliki arahan dalam pemanfaatan ICT dalam menunjang kelancaran pembelajaran melalui daring yang lebih aktif dan kreatif (Efendi dan Utami, 2019).

Berdasarkan arahan pemerintah Indonesia melalui Kemendikbud dan Kemenristekdikti contoh dari pengupayaan pengembangan pendidikan di Indonesia adalah dengan mengembangkan Keterampilan Abad 21 (21 ${ }^{\text {st }}$ Century skills) serta dengan menerapkan Blended/Hybrid Learning pada proses dan kegiatan pembelajaran. Adapun keterampilan dalam pembelajaran Abad 21 yaitu keterampilan hidup dan berkarir, keterampilan belajar dan berinovasi, keterampilan teknologi dan media informasi (Belmawa, 2019).

Pada era 4.0 setiap pengajar yaitu guru maupun dosen harus dapat memiliki inovasi pada metode pembelajaran (Megahantara, 2017). Sehingga dengan memanfaatkan ICT dapat membantu para pengajar dalam berinovasi untuk melaksanakan pembelajaran Blended (Blended Learning), adalah kombinasi pembelajaran melalui tatap muka dengan pembelajaran berbasis teknologi (online) (Banados, 2006). Adapun beberapan keunggulan dalam kegiatan pembelajaran dengan menggunakan Blended adalah: memberikan ruang serta kesempatan yang yang banyak dalam belajar, terdapat banyak informasi yang mendukung sesuai bidang informasi yang diinginkan, serta mendukung kegiatan interaksi dan kolaborasi antar murid (GIHE, 2010).

Di tahun 2014, Google juga melakukan pengembangan LMS secara gratis dengan sebutan Google Classroom (GC). GC adalah alat pembelajaran Blended yang memudahkan pendidikan di dunia. GC dapat merancang, membagikan, dan mengelompokkan materi atau tugas tanpa kertas (Bell, 2015). Pembelajaran dengan menggunakan GC terdapat banyak keunggulan yaitu proses pengaturan yang efektif, efisien dalam komunikasi, penyimpanan data serta berbagi sumber informasi. Sehingga ini mendorong Tim PKM untuk memberikan pelatihan dan pendampingan pada guru untuk menggunakan GC dalam kegiatan pembelajaran.

Namun, berdasarkan beberapa tinjauan pustaka, penggunaan GC belum begitu di aplikasikan oleh para pendidik yaitu guru maupun dosen. Hal itu dikarenakan beberapa macam faktor teknis, taktis, ekonomi, dan sosial. Saat ini kegiatan pembelajaran hanya melalui Whats' up. Materi dan tugas disampaikan melalui media Whats' up. Hal ini terjadi dikarenakan kurangnya wawan guru dalam memanfaatkan ICT dalam pembelajaran melalui daring. Sehingga guru merasa kesulitan untuk menerapkan pembelajaran berbasis Teknologi.

Melihat masalah yang ada, kegiatan PKM ini memilki tujuan yaitu untuk menerapkan penggunaan GC secara optimal dalam kegiatan pembelajaran. Adapun tujuan yang lebih spesifik dari PKM ini adalah: (1) Menaikkan kompetensi guru-guru di SDN 41 dalam pengelolaan pembelajaran berbasis Google Classroom; (2) Meningkatkan mutu dan kualitas materi dan instrumen dengan menggunakan Google Form.

\section{METODE PENELITIAN}

Pada kegiatan pengabdian kepada masyarakat ini dilaksanakan di SDN. 41 yang beralamatkan di jalan Mawar Talang Ratu Ujung Kelurahan 20 Ilir Kecamatan Ilir Timur I Palembang. Pelatihan Google Classroom dilaksanakan pada hari Jum'at, tanggal 2 Oktober 
2020. Peserta kegiatan ini merupakan seluruh guru-guru SDN. 41 Palembang, yang berjumlah 17 orang. Bentuk pendekatan yang dilaksanakan pada kegiatan Pelatihan Penggunaan Google Classroom dalam mengoptimalkan pembelajaran e-learning di SDN. 41 Palembang diuraikan secara detail sebagai berikut: 1) memberikan informasi pengetahuan mendasar mengenai Penggunaan Google Classroom, 2) memberikan pelatihan dalam pemberian materi secara langsung dalam pengoperasian Google Classroom melalui proyektor. Beberapah tahapan penting yang harus di persiapkan dalam melaksanakan kegiatan PKM adalah: 1) tahap analisis, 2) tahapan penyusunan materi, 3) tahapan pelaksanaan, 4) tahapan penyusunan laporan kegiatan.

\section{Tahapan Analisa}

Pada tahap ini kami mempersiapkan hal-hal teknis seperti tempat ruangan dan waktu kepada kepala sekolah selaku mitra tempat PKM. Selain itu kami juga melakukan wawancara serta diskusi mengenai kendala-kendala guru SDN. 41 Palembang serta harapan guru-guru agar dapat mengikuti perkembangan teknologi dalam melaksanakan pembelajaran melalui daring. Pada tahap ini dihadiri oleh guru-guru dari berbagai mata pelajaran dan kepala sekolah. Sehingga kami menentukan media Google Classroom sebagai sebagai bagian dari media ICT yang dapat diterapkan oleh SDN. 41.

\section{Tahapan Penyusunan Materi}

Tim pelaksana melakukan penyusunan materi sesuai dengan tahapan analisa atau observasi sebelumnya. Dalam tahap ini, tim membuat pedoman materi dalam penggunaan Google Classroom dari beberapa referensi. Berikut adalah panduan penggunaan Google Classroom bagi para guru.

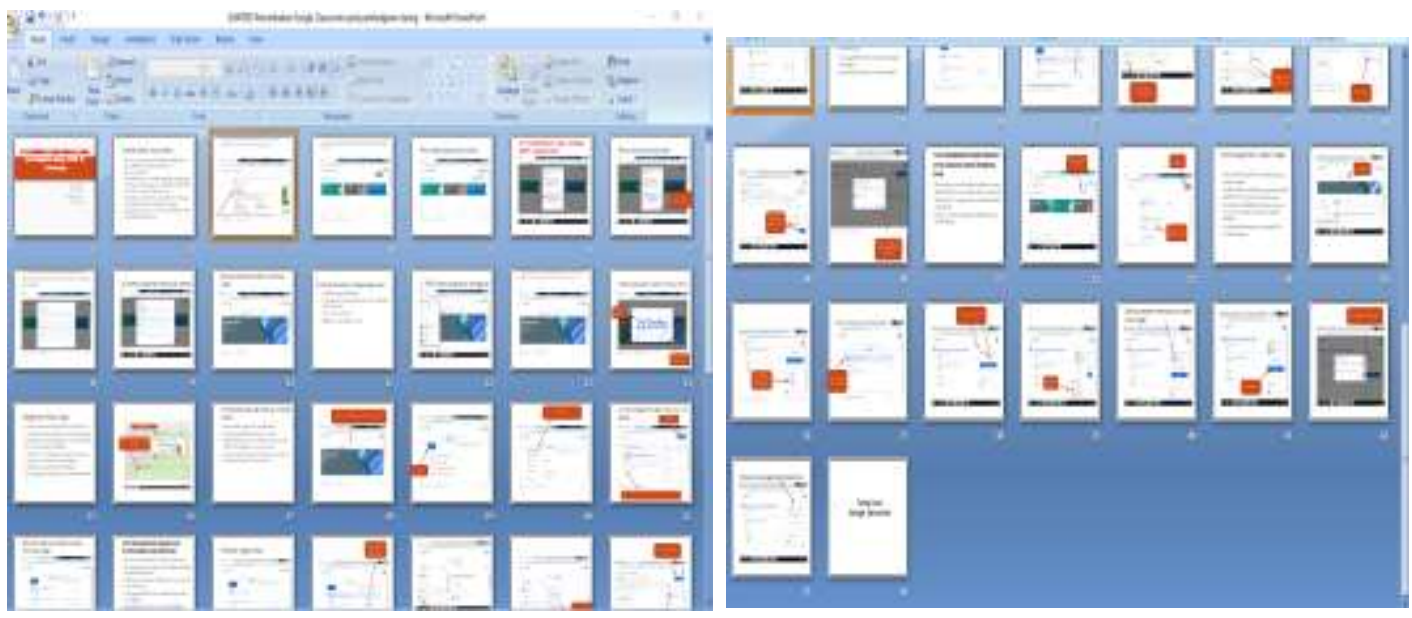

Gambar 1. Handout untuk peserta

1. Tahapan Pelaksana

Dalam tahapan ini, pemakalah menjelaskan hal-hal mengenai GC serta keuntungan-keuntungan yang dapat diperoleh oleh guru dan siswa dalam 
menggunakan media tersebut. Selanjutnya pemateri memberikan pengetahuan pembuatan akun yang merupakan tahap awal sebelum dapat menggunakan GC. Para guru diminta untuk menggunakan smartphone mereka masing-masing serta mulai mengakses Google Classroom. Setiap guru sangat ingin tahu dan langsung mempraktikkan pembuatan Google Classroom tersebut. Setelah itu guru memahami beberapa hal terkait metode pembelajaran menggunakan Google Classroom yaitu: membuat tugas, quis, serta mengoreksi nilai quis.

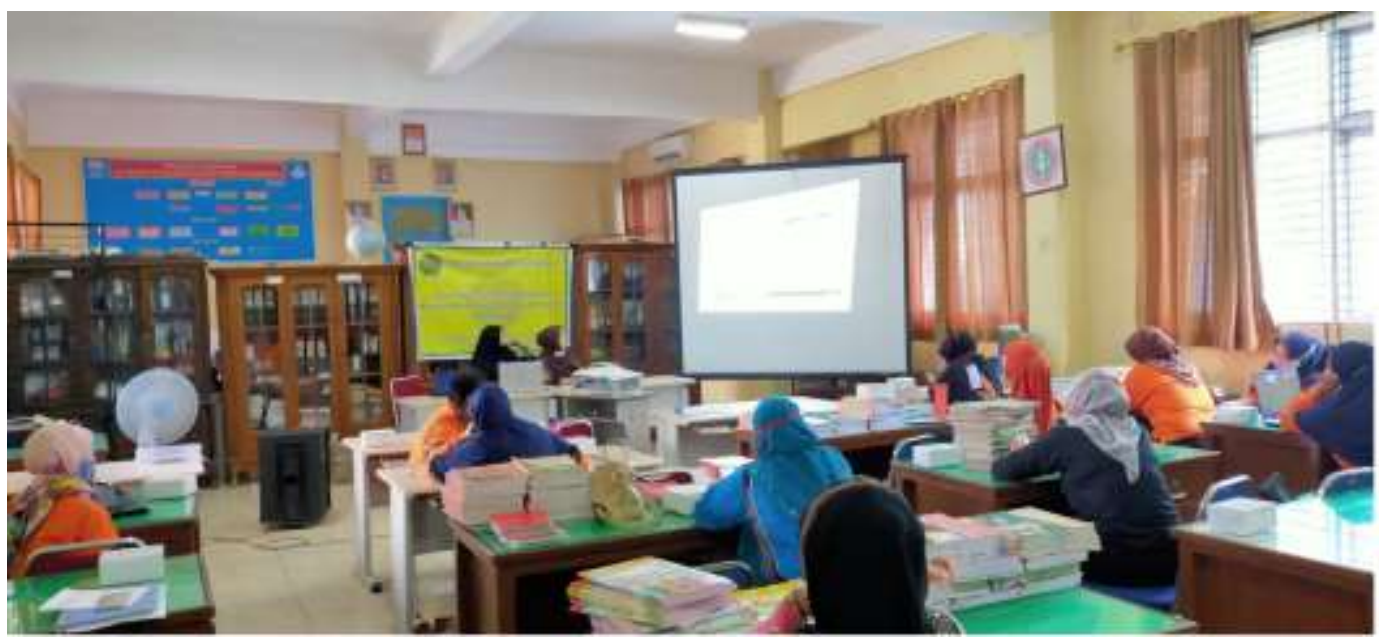

Gambar 2. Pelatihan Google Classroom

2. Tahapan penyusunan laporan kegiatan

Pada tahap ini, tim membuat laporan kegiatan serta hasil kegiatan pengabdian yang sudah dilakukan. Sehingga hasil kegiatan yang dilakukan dibuat menjadi jurnal pengabdian pada masyarakat.

\section{HASIL DAN PEMBAHASAN}

Kegiatan PKM ini dilakukan dengan cara tatap muka. Dengan menggunakan metode demonstrasi, diskusi, tanya jawab, dan penugasan. Para peserta secara langsung melakukan praktik membuat Google Classroom sambil mendengarkan penjelasan yang diberikan oleh tim. Dalam hal ini diharapkan pesrta dapat memahami konsep serta prosedur dalam penggunaan google classroom. Kegiatan ini menghasilkan modul dalam bentuk soft file PPT yang dapat membantu para guru dalam pelaksanaan pelatihan penggunaan Google Classroom.

Kegiatan PKM ini dimulai dengan kata sambutan yang diberikan oleh kepala sekolah. Selanjutnya adalah ucapan terimakasih yang diberikan oleh ketua tim pelaksanaan PKM yaitu Asti Gumartifa, S.Pd., M.Pd. Serta kegiatan paparan materi yang diberikan oleh masing-masing tim sesuai bagiannya. Berikut dokumentasi pembukaan kegiatan dan pemaparan materi yang dapat dilihat pada Gambar 3 dan 4. 


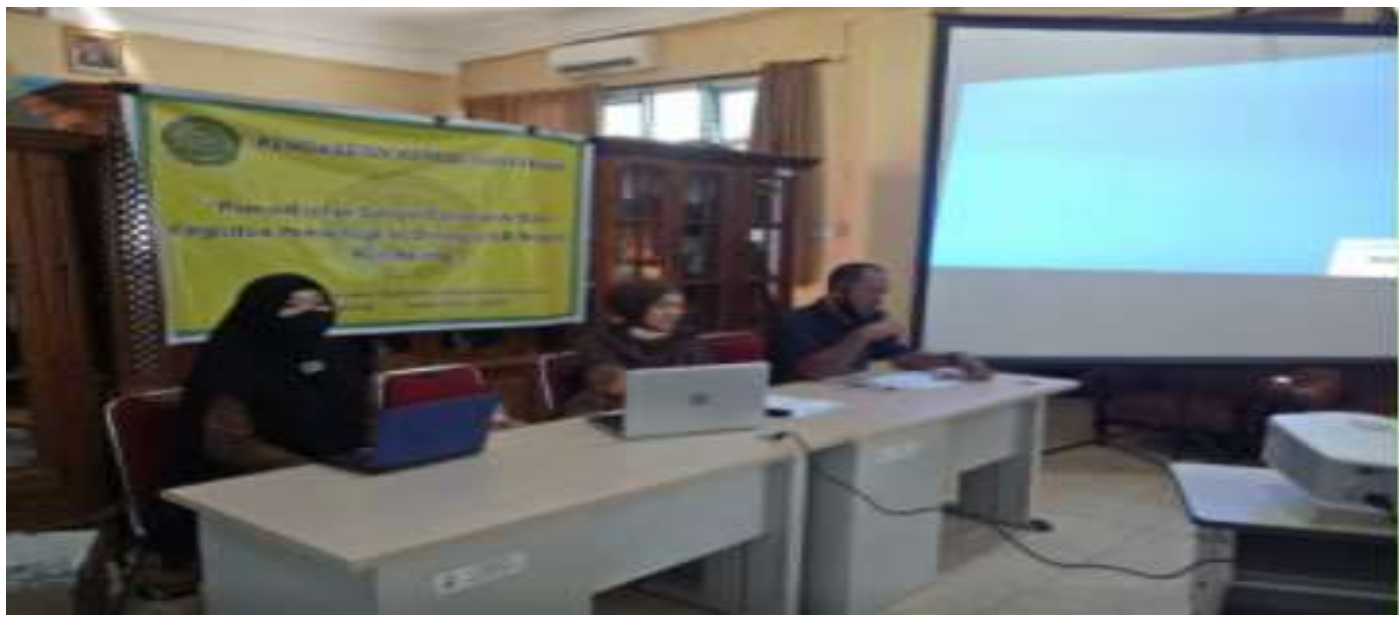

Gambar 3. Pembukaan kegiatan PKM oleh kepala sekolah SDN 41

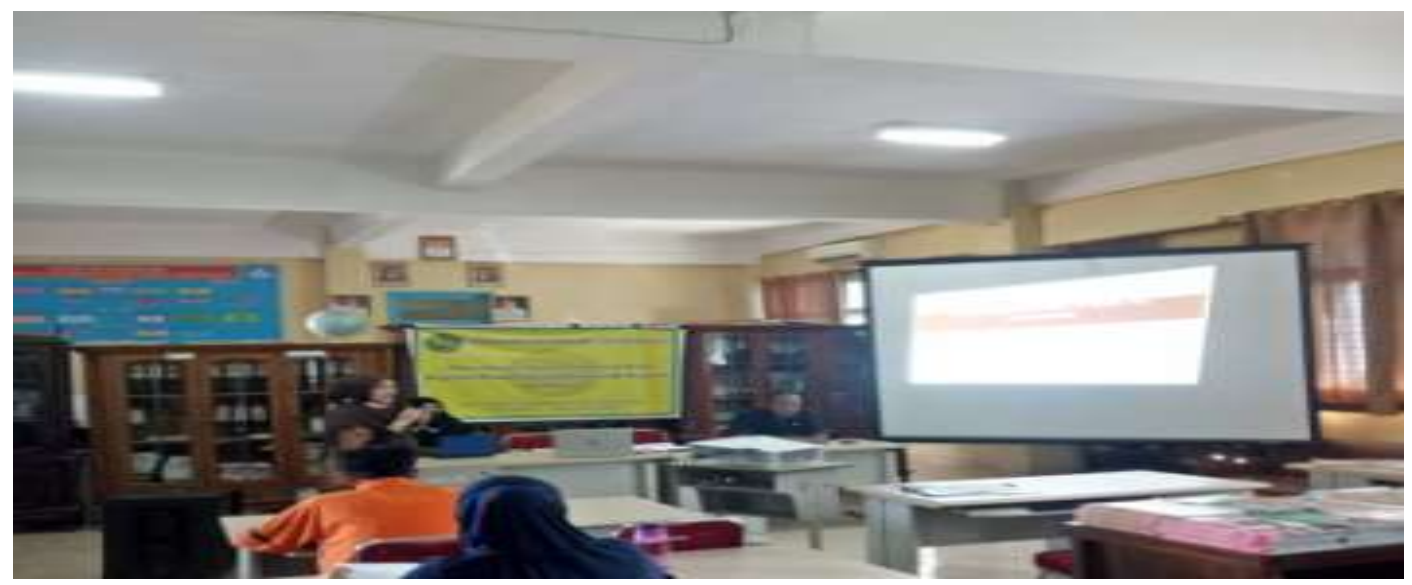

Gambar 4. Penyampaian materi mengenai Google Classroom

Materi pelatihan meliputi: pengenalan, prosedur penggunaan, serta format konstruksi pembelajaran dengan menggunakan Google Classroom. Setelah itu adanya diskusi serta praktik secara langsung dalam pengaplikasian Google Classroom. Berikut dokumentasi praktik penggunaan Google Classroom dapat dilihat pada gambar 5 .

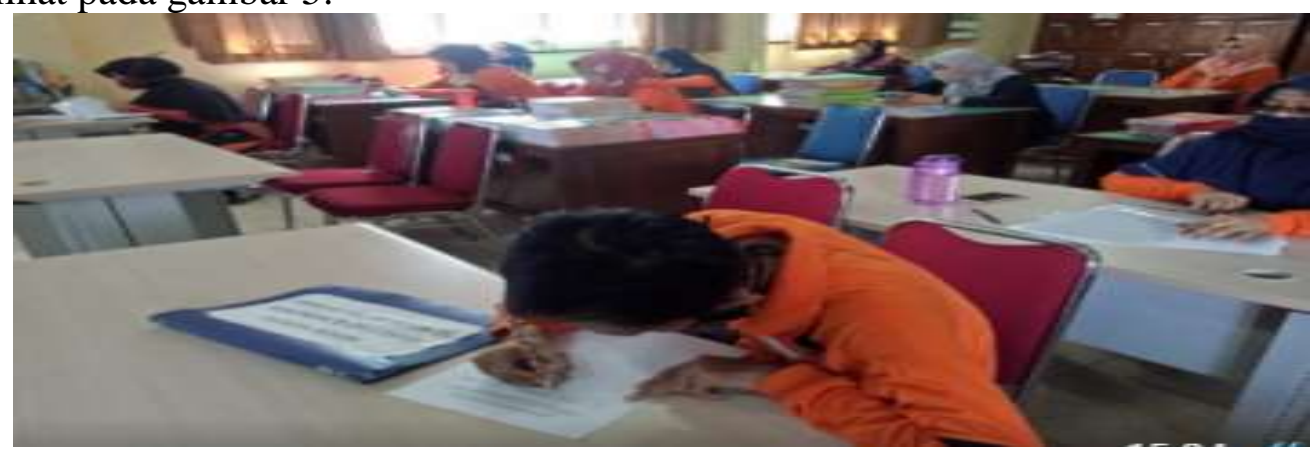

Gambar 5. Penyampaian materi mengenai Google Classroom 
Seminar Nasional Penelitian dan Pengabdian kepada Masyarakat Universitas Sang Bumi Ruwa Jurai Tahun 2020

Pada kegiatan PKM ini sangat disambut seluruh dosen dengan rasa antusias tinggi. Hal itu dapat dilihat dari keaktifan setiap guru pada setiap proses kegiatan serta guru-guru juga langsung bertanya mengenai hal yang membuat mereka belum dapat melanjutkan ke step lanjutan dalam pengaplikasian Google Classroom. Sebagian besar dari guru-guru SDN. 41 mengungkapkan bahwa penggunaan Google Classroom sangat membantu merekan untuk tetap dapat melaksanakan pengajaran yang aktif dan optimal tanpa terbatas ruang dan waktu. Sehingga hal ini sangat sesuai dengan hasil penelitian sebelumnya yang menyatakan bahwa terdapat banyak sekali keunggulan dari penggunaan Google Classroom (Savitri, 2019).

\section{KESIMPULAN}

Pelatihan penggunaan Google Classroom dalam mengoptimalkan proses pembelajaran berjalan dengan lancar. Dalam kegiatan ini memberikan kontribusi untuk meningkatkan wawasan guru untuk dapat melakukan proses pengajaran yang berbasis teknologi dengan optimal. Sehingga penggunaan Google Classroom diharapkan dapat membuat kegiatan dan proses pembelajaran menjadi efektif dan optimal, serta dapat memberikan dampak baik pada hasil belajar siswa.

\section{DAFTAR PUSTAKA}

Belmawa. (2019). Panduan Penyusunan Kurikulum Pendidikan Tinggi di Era Industri 4,0. Jakarta: Direktorat Belmawa, Kemenristekdikti.

Banados, E.(2006). A blended-learning pedagogical model for teaching and learning EFL successfully through an online interactive multimedia environment. CALICO Journal 23/3. pp. 533-550.

GIHE. (2010). Getting Started with Blended Learning. Griffith: Griffith University

Bell, K. (2015). The Teacher's Guide to Google Classroom. Texas: Shake Up Learnig, LLC

Savitri, D. I. (2019). Penggunaan pembelajaran 4.0 berbantuan aplikasi google classroom dan google form dalam mata kuliah ilmu sosial budaya dasar. Jurnal Borneo Saintek, 2(1), 20-25.

Megahantara, G.S. (2017). Pengaruh teknologi terhadap pendidikan di abad 21. Yogyakarta : Universitas Negeri Yogyakarta.

Efendi, Y., \& Utami, N. (2019). Pengukuran efektifitas pembelajaran menggunakan media e-learning google classroom (SMK Sulthan Muazzamsyah Pekanbaru). In Prosiding Seminar Nasional Computation Technology and its Aplication, 1, 2427. 